\title{
Development of a Health Policy Elective for Medical Students During the COVID-19 Pandemic: A Pilot Study
}

Rebecca Walton, BS | Alexandra Greenberg, MS, MSPH | Daniel Ehlke, PhD | Orlando Solá, $\mathrm{MD}, \mathrm{MPH}$

PRiMER. 2020;4:29.

Published: 10/15/2020 | DOI: 10.22454/PRiMER.2020.557079

\section{Abstract}

Introduction: In Central Brooklyn, Downstate Health Sciences University (DHSU) serves a diverse population that has experienced worsening rates of chronic disease and elevated rates of morbidity and mortality related to the COVID-19 pandemic. The medical community has shown an interest in addressing clinical and nonclinical disparities impacting patients' health and safety. As such, health policy knowledge is of special importance during a time of social and political unrest. Health policy and advocacy are listed in medical education guidelines, but there is a lack of standardized guidelines for implementation of a robust health policy curriculum within the rigors of clinical education.

Methods: Faculty from the Department of Family Medicine and the Department of Health Policy and Administration devised a health policy curriculum to be delivered virtually in the wake of COVID-19related quarantine. To assess the effectiveness of the curriculum, we administered pre- and postsurveys composed of learning objectives placed on a 5-point Likert scale, at each learning session.

Results: The results of these surveys showed an increase in confidence in the learning objectives of each educational session.

Conclusion: This pilot study warrants further research to fully assess the effect of a health policy curriculum on students' confidence in health policy knowledge and skills.

"Education is the most powerful weapon which you can use to change the world."

-Nelson Mandela

\section{Introduction}

Downstate Health Sciences University (DHSU) serves a diverse ethnic and economically disadvantaged community in Central Brooklyn, New York, with higher rates of economic adversity compared to national 
averages. ${ }^{1,2}$ Consequently, patients in this community suffer from unique health disparities in rates of maternal-fetal mortality, metabolic disease, and effects from the COVID-19 pandemic. $^{3-5}$

Health policy and advocacy referenced in medical educational guidelines ${ }^{6,7}$ encourage physicians to reach beyond the conventional clinical format to address the myriad social determinants that affect patient health. These skills are especially important as our communities are shaken by ongoing political, social, and economic unrest. We believe that integrating health policy into medical education will empower future health care leaders to navigate institutional, local, and national obstacles to providing high-quality patient care.

Although several medical schools have developed policy curricula, few take a comprehensive approach, and no validated guidelines exist for implementing such a course. While $94 \%$ of medical schools offer some form of policy education, the amount and extent of coursework varies, with an average of 14 hours over 4 years. ${ }^{8}$ In a survey conducted by Malik et al, ${ }^{9} 96 \%$ of medical students sampled reported no current or previous activity in health policy, with $61 \%$ willing to undertake a future role. Common barriers to student involvement included lack of knowledge and time and an unawareness of available opportunities. ${ }^{9}$

In response to these deficiencies, faculty from the Department of Family Medicine and the Department of Health Policy and Administration developed a course to augment existing policy training opportunities. The COVID-19 pandemic highlighted the importance of health policy knowledge and created a need for remote learning that met existing educational standards. The development and implementation of this course was therefore expedited in order to meet these needs.

\section{Methods}

A 4-week course was offered to rising fourth-year medical students as a remote course during the pandemic. As the school transitioned to virtual learning, a list of available remote courses was sent to the students, that included the Health Policy elective. Ultimately, the course was held over the span of 3 months with 12 students enrolled per month.

The curriculum outline ${ }^{10}$ details the sessions. Asynchronous sessions are prerecorded lectures focusing on creating a health policy fund of knowledge. The synchronous sessions allow learners to reflect on the recorded content and develop specific competencies meant for use in pursuing their policy agenda. Opendiscussion sessions focusing on current topics create an informal venue for learners to share in freeranging discussion. A writing workshop allows learners to practice health policy writing with one-on-one mentoring, with completed articles submitted to a peer-reviewed institutional policy newsletter. During the resolution writing workshop, learners are guided through cognitive models that assist in the development of policy proposals, followed by a review of parliamentary processes and the production of a policy resolution with associated implementation strategy.

To assess the impact of this 4-week elective, we provided pre- and postlecture surveys using a 5-point Likert scale, with questions derived from each session's learning objectives. Surveys were anonymous and voluntary, and provided via Qualtrics. ${ }^{11}$ We performed a paired-sample Wilcoxon signed-rank test to determine whether there was a significant difference in Likert scores reported by participants before vs after educational sessions. Surveys were voluntary, thus the number of students who had attended the session and completed both the pre- and postsurvey varied. We also collected and analyzed advocacy content created by learners, including articles and resolutions, for professionalism and content.

Our institutional review board (IRB) reviewed this study and determined it to be exempt. 


\section{Results}

We found that 6-10 participants (number varied by session) completed both pre- and postsurveys: health policy basics, health financing, American health policy, LGBTQ+ health policy, resolution writing, and the writing workshop. We chose these sessions for analysis because of the availability of matched pre- and postsurvey results collected for six or more students, as well as the desire to evaluate both lecture and workshop sessions. We measured a significant increase $(P<.05)$ for all Likert-scale questions before and after these lectures (Table 1).

The improvement in median pre- vs postsession scores ranged from 0.5 to 3 . This significant increase in score indicates students on average reported an increase in confidence in their knowledge and skills relating to important health policy topics, as defined by session learning objectives.

\section{Conclusions}

The survey responses show an increase in confidence in health policy comprehension and skills. However, this pilot study has notable limitations. Internal validity was affected by the small sample size and our dependence on participants' self-assessment, and selective bias may have affected the pool of learners who elected to take the health policy course in lieu of alternative remote learning opportunities. Another limitation stems from this course not being required for all medical students, but rather offered as a voluntary elective. Therefore, our sample is self-selected, as the participants may have a preexisting interest in the content. Finally, our outcomes were based on self-reported feedback, making this a Kirkpatrick level 2 assessment. This low level of assessment is another limitation.

Moving forward, we will expand this curriculum to a larger audience in DHSU, including students and residents. Once allowed, synchronous sessions will transition to in-person, where programs such as visits to local elected officials can resume. Data gathered from implementation of the full curriculum will provide guidelines for the integration of similar content in general medical and postgraduate education.

There is a persistent need for health policy reform, and COVID-19 and the Black Lives Matter movement have highlighted the need for political advocacy from the medical community. Nevertheless, there is lack of standardized guidelines for implementing health policy curriculum that combines the competencies necessary for effective advocacy. The findings from this pilot study warrant further investigation into the necessity and utility of health policy education for medical students.

\section{Tables and Figures}


Table 1: Changes in Pre- and Postsurvey Responses

\begin{tabular}{|c|c|c|c|c|c|}
\hline Lecture/Workshop & $\begin{array}{l}\text { How much confidence do } \\
\text { you have in your ability to... }\end{array}$ & $\begin{array}{l}\text { Premedian } \\
\text { Score }\end{array}$ & $\begin{array}{l}\text { Postmedian } \\
\text { Score }\end{array}$ & $\begin{array}{l}\text { Pre-Post } \\
\text { Change }\end{array}$ & P Value* \\
\hline \multirow{6}{*}{$\begin{array}{l}\text { Health policy basics } \\
(n=8)\end{array}$} & $\begin{array}{l}\text { Understand the relevance of health } \\
\text { policy in medicine }\end{array}$ & 1 & 3 & 2 & .015 \\
\hline & $\begin{array}{l}\text { Name examples of physician } \\
\text { professionals in health policy }\end{array}$ & 1 & 3 & 2 & .017 \\
\hline & $\begin{array}{l}\text { Describe the types of insurance } \\
\text { and insurers in the United States }\end{array}$ & 2 & 3 & 1 & .104 \\
\hline & $\begin{array}{l}\text { List educational and/or career } \\
\text { options in health policy }\end{array}$ & 1 & 3 & 2 & .016 \\
\hline & $\begin{array}{l}\text { List competencies that overlap } \\
\text { between health policy and } \\
\text { academic medicine }\end{array}$ & 1 & 3 & 2 & .011 \\
\hline & $\begin{array}{l}\text { Describe the CDC framework } \\
\text { for the development of policy } \\
\text { interventions }\end{array}$ & 1 & 3 & 2 & .011 \\
\hline \multirow{4}{*}{$\begin{array}{l}\text { Health care finance } \\
(n=6)\end{array}$} & $\begin{array}{l}\text { Identify the major payers of health } \\
\text { care in the United States }\end{array}$ & 2 & 3.5 & 1.5 & .046 \\
\hline & $\begin{array}{l}\text { Illustrate the relationships between } \\
\text { private and public payers of care }\end{array}$ & 2 & 3 & 1 & .034 \\
\hline & $\begin{array}{l}\text { Describe the role of managed care } \\
\text { within health care systems }\end{array}$ & 1.5 & 3 & 1.5 & .026 \\
\hline & $\begin{array}{l}\text { Assess proposals for reform of } \\
\text { public and private payers }\end{array}$ & 2 & 3 & 1 & .024 \\
\hline \multirow{6}{*}{$\begin{array}{l}\text { The American health } \\
\text { care system }(n=9)\end{array}$} & $\begin{array}{l}\text { Identify factors creating conditions } \\
\text { for high-quality care to be } \\
\text { unequally distributed }\end{array}$ & 1 & 2 & 1 & .006 \\
\hline & $\begin{array}{l}\text { Identify the factors increasing the } \\
\text { costs of health care }\end{array}$ & 2 & 4 & 2 & .011 \\
\hline & $\begin{array}{l}\text { Name at least three public and } \\
\text { private payers of health care }\end{array}$ & 2 & 4 & 2 & .023 \\
\hline & $\begin{array}{l}\text { Discuss how the health care } \\
\text { payment system developed over } \\
\text { time }\end{array}$ & 2 & 4 & 2 & .026 \\
\hline & $\begin{array}{l}\text { Evaluate the effectiveness of } \\
\text { interventions to lower health care } \\
\text { costs while expanding coverage } \\
\text { (ie, ACA) }\end{array}$ & 2 & 4 & 2 & .016 \\
\hline & $\begin{array}{l}\text { Explain how disparate forces form } \\
\text { the American health care system }\end{array}$ & 2 & 4 & 2 & .006 \\
\hline
\end{tabular}

(Continued on next page) 
Table 1: Continued

\begin{tabular}{|c|c|c|c|c|c|}
\hline Lecture/Workshop & $\begin{array}{l}\text { How much confidence do } \\
\text { you have in your ability to... }\end{array}$ & $\begin{array}{l}\text { Premedian } \\
\text { Score }\end{array}$ & $\begin{array}{l}\text { Postmedian } \\
\text { Score }\end{array}$ & $\begin{array}{l}\text { Pre-Post } \\
\text { Change }\end{array}$ & PValue* \\
\hline \multirow{4}{*}{$\begin{array}{l}\text { LGBTQ+ health policy } \\
(n=8)\end{array}$} & $\begin{array}{l}\text { List commonly accepted terms } \\
\text { related to sexuality and gender } \\
\text { identity }\end{array}$ & 3 & 3.5 & 0.5 & .020 \\
\hline & $\begin{array}{l}\text { Discuss policy topics relevant to } \\
\text { LGBTQ+ health care }\end{array}$ & 2 & 3 & 1 & .009 \\
\hline & $\begin{array}{l}\text { Understand how national and } \\
\text { local policies affect LGBTQ+ } \\
\text { communities in Central Brooklyn }\end{array}$ & 2 & 3 & 1 & .007 \\
\hline & $\begin{array}{l}\text { List advocacy opportunities for } \\
\text { students and residents }\end{array}$ & 2 & 3 & 1 & .009 \\
\hline \multirow{4}{*}{ Resolution writing $(n=9)$} & $\begin{array}{l}\text { Identify a problem amenable to a } \\
\text { policy resolution }\end{array}$ & 2 & 3 & 1 & .017 \\
\hline & $\begin{array}{l}\text { Complete the literature review } \\
\text { necessary to write a policy } \\
\text { resolution }\end{array}$ & 2 & 3 & 1 & .040 \\
\hline & $\begin{array}{l}\text { Develop a testimony pertaining to } \\
\text { a specific resolution }\end{array}$ & 1 & 3 & 2 & .017 \\
\hline & $\begin{array}{l}\text { Develop a strategy for resolution } \\
\text { policy implementation }\end{array}$ & 2 & 3 & 1 & .042 \\
\hline \multirow{4}{*}{$\begin{array}{l}\text { Writing workshop } \\
(n=10)\end{array}$} & $\begin{array}{l}\text { Discuss the role of communication } \\
\text { in academia and health policy }\end{array}$ & 2 & 3 & 1 & .005 \\
\hline & $\begin{array}{l}\text { Understand how to identify and } \\
\text { describe your target audience }\end{array}$ & 2 & 3 & 1 & .011 \\
\hline & $\begin{array}{l}\text { Understand how to write a policy } \\
\text { editorial }\end{array}$ & 0 & 3 & 3 & .005 \\
\hline & $\begin{array}{l}\text { Understand how to write a policy } \\
\text { review }\end{array}$ & 0 & 3 & 3 & .004 \\
\hline
\end{tabular}

*Wilcoxon signed-rank test for significant difference between presurvey and postsurvey median score.

Abbreviations: CDC, Centers for Disease Control and Prevention; ACA, Affordable Care Act; LGBTQ+, lesbian, gay, bisexual, transgender, queer, and other.

\section{Corresponding Author}

Orlando Solá, MD, MPH

\section{Author Affiliations}

Rebecca Walton, BS - SUNY Downstate Health Sciences University, Brooklyn, NY

Alexandra Greenberg, MS, MSPH - SUNY Downstate Health Sciences University, Brooklyn, NY

Daniel Ehlke, PhD - SUNY Downstate Health Sciences University, Brooklyn, NY

Orlando Solá, MD, MPH - SUNY Downstate Medical Center, Brooklyn, NY

\section{References}

1. United States Census Bureau. King's County (Brooklyn Borough), New York. https://www.census.gov /quickfacts/kingscountybrooklynboroughnewyork. Accessed June 8, 2020.

2. United States Census Bureau. United States. https://www.census.gov/quickfacts/fact/table /US/PST045219. Accessed June 8, 2020.

3. Webb Hooper M, Nápoles AM, Pérez-Stable EJ. COVID-19 and racial/ethnic disparities. JAMA. 2020;323(24):2466-2467. doi:10.1001/jama.2020.8598

4. National Academies of Sciences. The State of Health Disparities in the United States. In: Weinstein JN, Geller A, Negussie Y, Baciu A, eds. Communities in Action: Pathways to Health Equity. 
Washington, DC: The National Academies Press; 2017:582.

5. Centers for Diesase Control and Prevention. Racial and Ethnic Disparities Continue in PregnancyRelated Deaths. https://www.cdc.gov/media/releases/2019/p0905-racial-ethnic-disparitiespregnancy-deaths.html. Published 2019. Accessed June 6, 2020.

6. Accreditation Council for Graduate Medical Education. Common Program Requirements. ACGME. https://www.acgme.org/What-We-Do/Accreditation/Common-Program-Requirements. Accessed May $29,2020$.

7. Liaison Committee on Medical Education. Standards, Publications, and Notification Forms. LCME. https://lcme.org/publications/. Accessed May 29, 2020.

8. Mou D, Sarma A, Sethi R, Merryman R. The state of health policy education in U.S. medical schools. N Engl J Med. 2011;364(10):e19. doi:10.1056/NEJMp1101603

9. Malik B, Ojha U, Khan H, Begum F, Khan H, Malik Q. Medical student involvement in health policy roles. Adv Med Educ Pract. 2017;8:735-743. doi:10.2147/AMEP.S147212

10. Walton R, Greenberg A, Ehlke D, Sola O. Health policy curriculum outline. STFM Resource Library. https://resourcelibrary.stfm.org/viewdocument/health-policy-curriculumoutline?CommunityKey=2751b51d-483f-45e2-81de-4faced0a290a. Published 2020. Accessed October 7, 2020.

11. Walton R, Greenberg A, Ehlke D, Sola O. Survey template. STFM Resource Library. https://resourcelibrary.stfm.org/viewdocument/survey-template?CommunityKey=2751b51d483f-45e2-81de-4faced0a290a. Published 2020. Accessed October 7, 2020.

Copyright $(2020$ by the Society of Teachers of Family Medicine 